\title{
A TUTELA DA PORNOGRAFIA PELA CORTE EUROPEIA DE DIREITOS HUMANOS: UMA ANÁLISE DO ASPECTO DA PROTEÇÃO DA MULHER EM SITUAÇÃO DE VIOLÊNCIA DE GÊNERO
}

THE APPROACH OF THE EUROPEAN COURT OF HUMAN RIGHTS TO PORNOGRAPHY: AN ANALYSIS UNDER THE ASPECT OF THE PROTECTION OF WOMEN SUFFERING GENDER VIOLENCE

\author{
Raisa Duarte da Silva Ribeiro \\ Renata da Silva Athayde Barbosa \\ Rodrigo de Souza Costa
}

\section{RESUMO}

Este artigo possui o objetivo de analisar o tratamento destinado à pornografia, como forma de expressão, pela Corte Europeia de Direitos Humanos. Para tanto, verifica se a tutela destinada a este instituto vem sendo realizada dentro de uma ótica de proteção dos direitos humanos das mulheres que se encontram em situação de violência de gênero em razão da pornografia. Num primeiro momento, se verificará a delimitação conceitual e os principais elementos da pornografia e sua distinção em relação a outros institutos semelhantes, cujo principal reflexo é a afetação à mulher, sua percepção de si mesma e pela sociedade, bem como as implicações de tais questões sobre os direitos humanos. Em seguida, serão apresentados alguns casos julgados pela Corte Europeia de Direitos Humanos envolvendo pornografia, em que será realizada uma análise acerca do tratamento depreendido por esse órgão jurisdicional e as consequências de uma subvaloração dessa questão para a implementação dos direitos humanos das mulheres, em especial a igualdade de gênero e as liberdades individuais. Por fim, conclui-se pela necessidade de revisão da 
perspectiva de afetação dos direitos humanos da mulher pela pornografia pelo mencionado órgão jurisdicional.

Palavras-chave: Pornografia. Violência de gênero. Corte Europeia de Direitos Humanos.

\section{ABSTRACT}

This paper aims to analyze the approach offered by the European Court of Human Rights to pornography as a form of expression. It tests whether the blindage provided is accordingly the protection of human rights belonging to women in gender violence due to pornography. In order to do so, firstly, it will face how pornography shows its differences from other institute which involves sexuality expressions and how it affects women, theirs perception about themselves and by Society, as well as its consequences for human rights. Secondly, the paper presents European Court of Human Rights cases where pornography was the main analysis object. As a conclusion, it is possible to determine the demand of a new perspective towards the level of compromise of women's human rights by pornography at the Court.

Keywords: Pornography. Gender violence. European Court of Human Rights.

\section{INTRODUÇÃO}

A pornografia desafia o Direito em muitos aspectos, a começar pela dificuldade em se definir seu conceito, passando pelo constante crescimento de sua indústria e terminando nos impactos negativos que gera para a sociedade. 0 aparecimento da imprensa e a redução de custos gráficos, por si só, já teriam sido suficientes para fazer o fenômeno de produção e consumo da pornografia ganhar novas proporções e alcançar um mercado consumidor de larga escala. Com a globalização, a difusão da internet e o crescimento do turismo, a pornografia passou a ser uma realidade social impactante e lucrativa para a vida de diversas pessoas.

0 Direito não precisa das respostas adequadas a qualquer realidade social, no entanto, a pornografia não pode ser vista como uma realidade social qualquer, pois ela gera impactos significativos para as pessoas envolvidas na sua confecção e para o seu mercado consumidor. 
Alguns dados podem ilustrar essa afirmação: 35\% de todos os downloads da internet são pornôs; sites pornô têm mais visitantes por mês do que Netflix, Amazon e Twitter combinados (CULTURE REFRAMED). Atualmente, a pornografia gera uma alta demanda e é facilmente acessada de forma online e, muitas vezes, gratuita.

Este trabalho se propõe não só a demonstrar os impactos da pornografia na construção da realidade social, como também sua relação com os direitos humanos da mulher. De outro lado, se investigará, através de levantamento de decisões proferidas pela Corte Europeia de Direitos Humanos, um dos órgãos jurisdicionais internacionais pioneiros na tutela dos direitos humanos, o tratamento jurídico destinado à produção e ao consumo dos materiais pornográficos. Assim, a questão a que se propõe é: o tratamento conferido pelo Direito à pornografia, através da Corte Europeia de Direitos Humanos, tem sido suficiente para proteção dos direitos humanos das mulheres?

A metodologia utilizada para tanto consistiu, de um lado, num levantamento bibliográfico que proporcionasse a compreensão dos embates existentes sobre a pornografia. Após explicitar as teorias feministas existentes em torno da temática em questão, adotou-se os posicionamentos de Andrea Dworkin e Catharine MacKinnon, que exteriorizam de forma mais visível e notória a situação de violência na qual as mulheres são submetidas em razão da produção e do consumo dos materiais pornográficos. Cabe ressaltar que, independentemente da polaridade existente dentro do próprio movimento feminista sobre a forma de tratamento adequado, compreende-se, de forma pacífica, que é necessária uma tutela protetiva das mulheres que se encontram em situação de violência.

De outro lado, utilizou-se também a pesquisa documental, com levantamento de casos julgados pela Corte Europeia de Direitos Humanos, na temática em questão.

O trabalho, através do método silogístico, pretende demonstrar suas premissas acerca da pornografia como forma de violência e verificar se o tratamento destinado à temática em questão pela Corte Europeia de Direitos Humanos é suficiente para a proteção dos direitos fundamentais das mulheres. 
Para tanto, em um primeiro momento, com base em pesquisas empíricas , demonstra-se a relação de causalidade entre a pornografia e a violência contra a mulher. Após, traz-se as principais correntes de disputas dentro do movimento feminista acerca da forma mais adequada de tratamento da pornografia pelo mundo jurídico.

Em sequência, exploram-se os argumentos utilizados pela Corte Europeia de Direitos Humanos nos seus julgados nos casos que envolvam a confecção e divulgação de materiais pornográficos e reflete-se sobre a suficiência das medidas adotadas para a proteção dos direitos humanos das mulheres que se encontram em situação de violência em decorrência da produção e do consumo da pornografia.

\section{A PORNOGRAFIA COMO FORMA DE VIOLÊNCIA DE GÊNERO}

Os dados acerca da difusão da pornografia mencionados acima significariam somente um negócio lucrativo ou uma nova febre comportamental que não deveria estar sujeito à legislação se não fosse um fato: a pornografia motiva, influencia e fornece parâmetros de comportamento sexual à sociedade.

Essa afirmação vem não só do fato de que crianças e adolescentes utilizam pornografia como uma fonte primária de informação sobre sua vida sexual, mas também de sua definição contida no dicionário Aurélio

Tratado acerca da prostituição. 2. Figura(s), fotografia(s), filme(s), espetáculo(s) obra literária ou de arte, etc., relativo a, ou que tratam de coisas ou assuntos obscenos ou licenciosos, capazes de motivar ou explorar o lado sexual do indivíduo. 3. Devassidão, libidinagem (FERREIRA, 1986, p. 1367). ${ }^{1}$

Assim, a pornografia não pode ser compreendida apenas como um fenômeno que se insere no "mundo das ideias", mas, ao contrário, deve ser enfrentada como uma prática constitutiva discursiva, pautada no primado da dominação masculina, que gera impactos na realidade social (RIBEIRO, 2017, p. 100 e ss.). 
Além disso, o conceito doutrinário de pornografia mostra que ela pode ser entendida como "um material criado por homens heterossexuais que combina sexo e/ou exposição da genitália com abuso ou degradação de mulheres de uma maneira que parece endossar, desculpar, ou encorajar tal comportamento" (RUSSELL, 1994, p 03) ${ }^{2}$, o que evidentemente destaca a capacidade da pornografia de definir o comportamento sexual das pessoas.

Por essa razão a pornografia requer uma interferência do Direito, pois o tipo de estímulo que ela se propõe a oferecer ao público é um problema social sério. Andrea Dworkin e Catharine MacKinnon, por sua vez, incluem no seu conceito, criado para proteger mulheres que sofrem de violência pornográfica, a circunstância de estimulação proporcionada pela pornografia: "a subordinação gráfica e expressa de mulheres por figuras e/ou palavras” (DWORKIN, MACKINNON, 1989, p. 36) 3 .

Cabe ressaltar que a pornografia objeto de análise do presente trabalho se refere a chamada pornografia tradicional, aquela produzida pela grande indústria pornográfica, compreendida como pode ser definida como a exibição gráfica de materiais sexuais, nos quais a sexualidade feminina seja mostrada de forma subalterna e haja a degradação de mulheres, deflagrada através de comportamentos agressivos, abusivos e degradantes, em contexto de dominação masculina, de maneira que se pareça endossar, encorajar ou normalizar a violência de gênero (RIBEIRO, 2017, p. 48-49). Assim, outras formas de exibição da sexualidade, como o erotismo e a pornografia feminista, não são alvo de análise pelo presente trabalho, na medida em que elas não geram, a priori, violência contra a mulher.

A pornografia promove a subordinação feminina, a começar pela forma como é produzida ${ }^{4}$ e a terminar pela imagem que ela vende. Esse é o aspecto crucial da pornografia que será analisada por este trabalho: o impacto da sua realização na proteção das mulheres que participam da realização destes materiais e a mensagem que ela envia a seus consumidores e demais destinatários, que constitui e reforça a realidade social, pautada no primado da dominação masculina.

A violência em face das mulheres é a mensagem transmitida e é a realidade social corroborada pela pornografia. Essas figuras já 
demonstram, por si só, a necessidade de interferência do Direito na temática em questão.

Neste momento, deve-se considerar que palavras e imagens produzidos pela pornografia não só expõem certo ponto de vista, como também criam a realidade social. A pornografia reforça o papel masculino de dominação ${ }^{5}$ e o papel feminino de subalternidade, colaborando para manter essa estandardização (RIBEIRO, 2017, p. 45). Ademais, a pornografia afeta ambos os gêneros já que cria um padrão de comportamento sexual a ser seguido por mulheres e homens ${ }^{6}$, apesar de afetar de modo mais intenso e severo as mulheres. Este trabalho vai analisar principalmente o lado da mulher, já que são elas que sentem com mais intensidade os aspectos negativos da pornografia, configurados nas diversas manifestações de violência de gênero.

De outro lado, algumas vozes podem se levantar para dizer que as pessoas têm o direito à intimidade para proteger suas preferências sexuais, em razão disso ser uma questão moral ou porque uma interferência do Direito nessa área restringiria a liberdade de expressão.

Ocorre que a pornografia é uma prática discursiva constitutiva, ou seja, o discurso externalizado pelos materiais pornográficos constroem realidades sociais (MACKINNON, 1996, p. 15). Todo discurso, de forma consciente ou não, possui objetivos específicos ${ }^{7}$. 0 discurso pornográfico transmite uma ideia sobre os gêneros e a sexualidade, tendo como consequência a perpetuação da lógica da dominação masculina ${ }^{8} 9$.

A pornografia apresenta as mulheres como objetos sexuais desumanizados, coisas ou bens de consumo ${ }^{10}$. As mulheres são desumanizadas, na medida em que suas características de reação a dor e de auto respeito são aniquiladas pelos materiais pornográficos ${ }^{11}$. Na pornografia, mulheres são chamadas por nomes pejorativos, são depreciadas e parecem gostar, porque pedem por mais ou porque sorriem. Ocorre que essas posturas são compradas pelo dinheiro, não havendo consensualidade senão através do capital (MACKINNON, 1996, p. 05). Além disso, na pornografia, as mulheres são exibidas sentindo prazer na violação, são machucadas, agredidas, lesionadas e se excitam com isso.

Além de serem desumanizadas, as mulheres são apresentadas como objetos sexuais. Observe que objetos não possuem vontade própria 
e que existem para satisfazer seus donos. Objetos provocam seu uso. Pela pornografia, as mulheres são vistas como objetos sexuais, porque provocam sexualmente os homens: seu acesso e seu uso sexual é ilimitado, elas existem para isso ${ }^{12}$.

A pornografia também animaliza as mulheres, que são exibidas como animais, chamadas por nomes de animais ou forçadas, em determinadas modalidades pornográficas, a terem relações sexuais com animais.

Ademais, a pornografia também reduz as mulheres às partes sexuais de seus corpos (DWORKIN, MACKINNON, 1989, p. 195). Essa fragmentação corporal faz com que os sentimentos e emoções das mulheres não sejam percebidas e corrobora para a sua desumanização ${ }^{13}$.

Por outro lado, a pornografia também traz a padronização de condutas sexuais. As relações sexuais ocorrem dentro de um script pré-definido, não existindo muitas variações (DWORKIN, 1989, p. xv; MACKINNON, 1989, p. 05). Estereótipos de mulher e de homem são criados pela pornografia. Não há liberdade para criação que envolva libertação sexual para ambos os gêneros, as únicas alterações possíveis se fazem dentro de um contexto de violência e de virilidade.

Assim, a pornografia gera violência de gênero, que se destina em face das mulheres, tanto em razão da sua produção, quanto em razão de seu consumo ${ }^{14}$. Cabe ressaltar que existem diversas modalidades de violência de gênero, podendo estas serem classificadas, exemplificativamente, em violência física, psicológica, sexual, patrimonial e moral ${ }^{15}$.

A violência física pode ser entendida como qualquer conduta ou ato corporal que ofensa a integridade ou a saúde física da vítima ${ }^{16}$. Este tipo de violência costuma ser identificada de forma mais notória, em razão de deixar marcas nos corpos das mulheres. Na pornografia, a violência física pode ser observada em diversos momentos, com a utilização de tapas com mãos abertas e demais agressões físicas perpetuadas. De acordo com pesquisas empíricas, cerca de $90 \%$ das cenas mais acessadas da internet contém comportamentos agressivos. Em 70\% da pornografia mais acessada, o homem está realizando a agressão e em $94 \%$ do tempo a agressão é dirigida para as mulheres. Cerca de $40 \%$ das cenas pornográficas mais acessadas contém tapas de mão abertas (CULTURE REFRAMED). 
A violência psicológica pode ser entendida como qualquer conduta que cause dano emocional, que diminua a autoestima, que prejudique ou perturbe o pleno desenvolvimento de sua vítima ou que vise degradar ou controlar suas ações, comportamentos, decisões e crenças. A violência psicológica pode ocorrer mediante ameaça, constrangimento, humilhação, manipulação, isolamento, vigilância constante, perseguição, ridicularização e limitação do direito de locomoção ou qualquer outro meio que cause prejuízo a saúde psicológica e a autodeterminação de suas vítimas ${ }^{17}$.

Na realização da pornografia, a violência psicológica pode ser observada já com relação a escolha do perfil das mulheres que participam da realização dos materiais pornográficos. De acordo com estudos empíricos, nos Estados Unidos, 65 a 75\% das mulheres que estão na prostituição e na pornografia nos foram abusadas na infância (DWORKIN, MACKINNON, 1989, p. 70). Além disso, são pessoas em regra pobres, com pouco acesso à educação, sendo a pornografia sua única opção. Para elas, de forma majoritária, a pornografia não foi questão de escolha livre, mas a sua única possibilidade.

Cabe mencionar também que há um percentual significativo de mulheres que estão na pornografia através de coação, pelo tráfico de mulheres, No Relatório Global sobre Tráfico de Pessoas, formulado no âmbito da Organização das Nações Unidas, em 2014, 53\% das vítimas, em termos globais, foram traficadas para fins de exploração sexual, sendo 97\% mulheres (UNODOC, 2014, p. 13).

De forma semelhante, o Relatório Global sobre Tráfico de Pessoas de 2016, referente ao período de 2012 a 2014, identificou cerca de 65 mil vítimas do tráfico internacional de pessoas, sendo $51 \%$ mulheres, $21 \%$ homens, $20 \%$ meninas e $8 \%$ meninos. Além disso, relatou que o período de 2007 a 2014, o tráfico para exploração sexual manteve-se entre 50 e $60 \%$, sendo, portanto, o maior objetivo desta conduta ilícita (UNODOC, 2016).

Nesse momento, cabe pontuar que não se desconsidera que existe uma parcela de mulheres que estão na pornografia e na prostituição de forma livre, aceitando as condições ofertadas pela indústria pornográfica por vontade própria e com capacidade de escolha, e que fazem extensa 
carreira no mercado pornográfico. Em tais casos, parece que deve preponderar a autonomia da mulher, que se desdobra também na capacidade de gerir da forma que quiser seu próprio corpo.

Por outro lado, majoritariamente, como os dados nos mostram, a indústria pornográfica explora mulheres vulneráveis. E a vulnerabilidade gera fortes vícios de consentimento. Sobre o consentimento, Cezar Roberto Bitencourt (2012, p. 339) e Guilherme de Souza Nucci (2016, p. 254) trazem como um dos seus pressupostos que a manifestação do ofendido seja livre, sem coação, fraude ou outro vício de vontade. Para que haja consentimento deve haver liberdade de escolha: entre duas ou mais possibilidades, definir aquela que melhor satisfaz meus projetos de vida. É difícil sustentar o consentimento em ambientes de vulnerabilidade, como ocorre nos casos de tráfico de pessoas e de pessoas em condições econômicas insuficientes.

Em algumas modalidades de pornografia, à exemplo da pornografia extrema ou violenta, em que como a produção de imagem sensual que objetiva a excitação sexual e contém elementos de ameaça a vida da pessoa, como sufocamento e agressão sexual sob ameaça de uma arma; ou causar feridas severas ao ânus, seios ou genitália da pessoa, como por exemplo a inserção de objetos afiadas na genitália da vítima, parece haver vício de consentimento. Juarez Tavares (2018, p. 269) assevera que ligado à disponibilidade do bem, deve se ter em conta que "se a conduta afetar também um bem jurídico ou interesse (sic) da coletividade, torna-se impossível o consentimento justificante". No caso da pornografia violenta, não se sustenta a existência de interesse público no exercício da vida sexual da mulher, mas observa-se a falta de consentimento na medida em que a mulher que se submete a sacrifícios físicos da ordem mencionada acima, o faz, em regra, por necessidade. Não bastasse isso, há autores que tratam a integridade física como bem jurídico indisponível (FRAGOSO, 2003, p. 192-193), o que impossibilitaria o consentimento da ofendida.

De forma oposta, no entanto, Gayle Rubin (1983, p. 181) traz críticas a capacidade de consentimento das mulheres que participam da pornografia, inclusive da pornografia sadomasoquista, porque, ao se sustentar que na pornografia hardcore parece haver vícios de consentimento em razão da violência, traça-se uma distinção entre o sexo 
aceitável e o não aceitável, isto é, entre práticas sexuais que podem ser consentidas e práticas sexuais que não podem ser consentidas.

Além do perfil das mulheres que estão na pornografia, a violência psicológica também é configurada através da padronização dos comportamentos sexuais, da exibição da sexualidade feminina como suja, dos xingamentos, do rebaixamento, da subalternidade e da depreciação das mulheres no contexto pornográfico.

A violência sexual refere-se à utilização de forma que limitem ou anulem a sexualidade de suas vítimas. Pode ser entendida como qualquer conduta que venha a constranger a vítima a presenciar, manter ou participar de relação sexual não desejada, ou que a induza a comercializar ou utilizar de qualquer forma a sua sexualidade, ou que a impeça de utilizar método contraceptivo ou que force ao matrimônio, à gravidez ou ao aborto, ou ainda que limite ou anule o exercício de seus direitos sexuais ou reprodutivos. A violência sexual pode ser realizada através da utilização de intimação, ameaça, coação ou uso da força. Ou ainda, mediante chantagem, suborno ou manipulação ${ }^{18}$

$\mathrm{Na}$ confecção da pornografia, com a padronização dos comportamentos sexuais e com a utilização do dinheiro como forma de consensualidade, observa-se uma nítida configuração da violência sexual. Em diversos filmes pornográficos, as mulheres são proibidas de terem relações sexuais com preservativos e são obrigadas a utilizarem métodos anticoncepcionais específicos (CULTURE REFRAMED), devem se comportar sexualmente dentro dos scripts sexuais determinados, comercializam seu corpo e sua sexualidade.

Conforme salientado, a pornografia traz a padronização de condutas sexuais, o que caracteriza uma forma de violência sexual. As relações sexuais ocorrem dentro de um script pré-definido (DWORKIN, 1989, p. 05), através da construção de estereótipos de mulher e de homem. Não há liberdade para criação que envolva libertação sexual para ambos os gêneros, as únicas alterações possíveis se fazem dentro de um contexto de violência e de virilidade. 0 prazer masculino é a única coisa que está em jogo: assim que o homem ejacula, a relação sexual é finda; o orgasmo feminino, exuberante e de proporções grotescas, apenas existe para corroborar a ideia da virilidade masculina (DINES, 2010, p. xviv). 0 
sorriso da mulher está sempre presente, não em razão do prazer sentido, mas da exigência dos pornógrafos, conseguida mediante o pagamento em dinheiro (MACKINNON, 1989).

Além disso, os direitos sexuais das mulheres também são anulados, na medida em que, uma vez assinado o contrato, tudo pode ser feito com relação à mulher para a confecção dos materiais pornográficos. 0 consentimento da mulher, ao assinar o contrato, firmado de forma escrita ou verbalmente, torna-se permanente e inquestionável, devendo ela realizar todos os atos que lhe são solicitados, para que possa receber pelo serviço sexual prestado.

A violência patrimonial se refere às condutas que configurem retenção, subtração, destruição total ou parcial dos objetos, instrumentos de trabalho, documentos pessoais, bens, valores, direitos ou recursos econômicos de suas vítimas, incluindo aqueles que sejam necessários para satisfazerem as suas necessidades ${ }^{19}$

Na confecção da pornografia, a violência patrimonial também pode ser observada em alguns momentos, quando ocorre a retenção do dinheiro das mulheres ou de seus documentos por seus agenciadores, a escolha da destinação de seus rendimentos para a compra específica de produtos e alterações de seus corpos, entre outros comportamentos.

A violência moral refere-se a qualquer conduta no sentido de imputar falsamente fato definido como crime $^{20}$ ou imputar fato ofensivo à reputação da vítima ${ }^{21}$, ou ainda, ofender a sua dignidade ou decoro 2223 .

Na realização da pornografia, a exibição da sexualidade feminina de forma subalterna ofende a sua dignidade, sendo configurada também a violência moral.

Estas definições de violência de gênero foram extraídas da lei no 11.340/06, editada pelo Brasil, popularmente conhecida como Lei Maria da Penha, que tutela os casos de violência doméstica e familiar contra a mulher. Apesar de ter um âmbito restrito de aplicação, os conceitos exarados no artigo 7ํ da mencionada legislação possuem um potencial expansivo, podendo ser utilizada de forma analógica para todas as formas de violência de gênero.

Observe que na pornografia essas modalidades de violência de gênero podem ocorrer de forma cumulativa ou separadamente. Mas, em 
todos os casos de materiais pornográficos tradicionais, pode-se visualizar uma ou mais condutas de violência.

Cabe ressaltar, ainda, que conforme salienta Catherine Mackinnon, a pornografia também gera efeitos negativos na vida das mulheres em razão do seu consumo. A pornografia gera intrusão mental inconsciente e manipulação física em seus consumidores (MACKINNON, 1996, p. 16). Por ser uma fonte de excitação a ser utilizada por seus consumidores como materiais de masturbação, a naturalização da violência é visualizada na prática. Além disto, os consumidores se tornam mais propensos a querer reproduzir na vida real aquilo que eles aprenderam na pornografia ${ }^{24}$.

0 questionamento acerca do que fazer com a pornografia permanece alvo de disputas dentro do próprio movimento feminista (PRADA, 2010, p. 7-26). De um lado, o feminismo radical defende a necessidade da abolição da pornografia, compreendida como uma prática política sexual, baseada no primado da perpetuação da lógica da dominação masculina, que gera violência contra as mulheres, conforme já salientado.

De outro lado, uma vertente do feminismo defende a posição pró-pornografia reconhecimento algumas das críticas destinadas pelo movimento anterior, mas chegando a uma conclusão diversa: sustentam a necessidade de regulamentação da pornografia, para que se garanta condições de trabalho favoráveis para as mulheres que dela participam, resgatando a capacidade das mulheres de decidir sobre o próprio corpo e se preocupando com as consequências negativas de uma eventual proibição (VANCE, 1989, p. 48; ECHOLS, 1983, p. 267 e ss). De forma mais contemporânea, defende-se a possibilidade de utilização subversiva da pornografia, com representações alternativas da sexualidade (PRECIADO, 2018; BUTLER, 1997).

Assim, o desafio que foi proposto ao Direito está relacionado à dificuldade de compatibilizar tais direitos e a necessidade de proteção de um grupo vulnerável que fica evidenciado pela pornografia, a mulheres. Nos Estados Democráticos, como o Direito se propõe a balancear os direitos humanos da mulher e a pornografia: respeitando o direito à pornografia, em defesa da liberdade de expressão, regulando-a, em defesa da proteção das mulheres, trazendo requisitos para a garantia do seu exercício, ou restringindo-a, em defesa da promoção da igualdade, 
da expressão de minorias silenciadas e da vedação à violência e discriminação.

\section{CORTE EUROPEIA DE DIREITOS HUMANOS, PORNOGRAFIA E PROTEÇÃO DA MULHER}

Para explicar e criticar parâmetros concretos, delimitamos o presente estudo na investigação da jurisprudência da Corte Europeia de Direitos Humanos sobre casos envolvendo pornografia. Os direitos humanos podem constituir um bom termômetro para se sentir o quão transformadoras as práticas políticas podem ser e, reconhecendo o sistema europeu de direitos humanos como o mais antigo e exponencial, a sua análise proporcionaria uma clara visão das respostas que estão sendo conferidas à questão da pornografia.

Levando em consideração a informação contida no item anterior, não se busca questionar se o Direito deve intervir ou não na questão da pornografia, mas sim verificar como essa intervenção deve ocorrer para a proteção dos direitos humanos das mulheres. Não há dúvidas de que a pornografia não é a causa da misoginia, entretanto, é um sintoma e um agente ativo em gerar um status de segunda classe para as mulheres ${ }^{25}$. E como qualquer sintoma terrível é importante curá-lo (DWORKIN; MACKINNON, p. 73).

Como uma preliminar a essa análise, é necessário afirmar que este debate encara a pornografia como uma prática danosa a mulher, não se enquadrando numa questão moral ou proporcionando uma nova versão de debate sobre autonomia do indivíduo traçado em Devlin vs. Hart ${ }^{26}$ (DWORKIN, 2006).

A versão tradicional da pornografia realiza uma mistura do seu conceito com o de obscenidade e essa confusão se apresenta somente porque, nesta visão, o problema da pornografia acaba sendo encarado pelo viés da moralidade. No entanto, a questão da pornografia que enseja a tutela jurídica não se refere a uma suposta afronta a moralidade sexual, mas sim a violência contra a mulher e a negação do estatuto de igualdade de gênero proveniente desses materiais. 
A pornografia é uma prática concreta, caracterizada como a gráfica representação de prostitutas, enquanto a obscenidade é uma ideia abstrata, requerendo um juízo de valor (DWORKIN, 1989, p. lvi). A obscenidade pode ser encarada como aquilo que fere o pudor ou que não deve ser mostrado, por razões estéticas; em outras palavras, aquilo que viola a moralidade sexual dominante, que é masculina (RIBEIRO, 2017, p.).

Os conceitos de pornografia e obscenidade só poderiam ser confundidos numa lógica em que se presuma ser a pornografia um assunto atinente a moral - o que não é sustentado pelo presente trabalho, à luz das teorias feministas -, em cujo caso ambos transgrediriam igualmente a moral sexual ${ }^{27}$. Não há discordância em relação à assunção de que, em uma sociedade liberal e democrática, lei e moral devem permanecer em sistemas separados. Especificamente no que se refere à intervenção, Roxin assevera que a imoralidade ou desaprovação ética não podem legitimar uma proibição criminal, como, por exemplo, na não punibilidade de práticas sexuais abjetas (ROXIN, 2008, p. 38). 0 autor aduz que o comportamento imoral desenvolvido na vida privada com consentimento não pode ser punido se não gerar qualquer consequência social de cunho negativo.

É precisamente nesta condição, desde que não gere consequência social, que o argumento falha em manter o Direito longe na questão da pornografia. De acordo com Diana Russel, o que é questionável sobre a pornografia é o abusivo e degradante retrato que ela gera das mulheres e da sexualidade feminina, não seu conteúdo sexual explícito (RUSSELL, 1994, p. 05).

Ao lado de vetores como a tolerância, diversidade e a liberdade, que regulam as práticas sexuais, a alteridade requer a identificação da visão do outro e o respeito às suas posições ideológicas. É a existência da alteridade e das diferenças que torna possível construir uma identidade, sem ela, as pessoas não existem como indivíduos (SILVA, 2000, p. 65).

0 argumento da alteridade, em verdade, ao invés de reforçar a liberdade sexual sem limites, mostra quão importante o outro é para a formação da identidade do indivíduo, significando que é exatamente esta a razão pela qual a pornografia não pode ser absolutamente desregulada, 
já que a mensagem transmitida pela pornografia é a que vai formar pessoas.

No cenário da Convenção Europeia de Direitos Humanos, a pornografia pode ser tratada por três diferentes vertentes. A primeira seria a de encarar o problema como algo enquadrado no direito à liberdade de expressão, contida em seu artigo 10; a segunda seria a de encaixar a pornografia no que se refere ao direito a vida privada, contida no artigo 8; e por fim a última possibilidade seria a de percebê-la no direito de estar livre de tratamento degradante, contido no artigo 3 (JOHNSON, 2014, p. 4).

Assim, se impõe a seguinte questão: a abordagem realizada pela Corte Europeia de Direitos Humanos está apta a proteger os direitos humanos das mulheres que estão na pornografia e que vivem consequências derivadas do consumo dos materiais pornográficos?

Para começar essa análise, enfrentar-se-á a questão da pornografia sob a perspectiva da liberdade de expressão. Para aqueles que defendem a ideia de que a pornografia é um direito, numa visão negativa da liberdade, a pornografia, apesar de ser ultrajante para homens e mulheres, deveria ser respeitada como forma de expressão, já que não importa o quão odiosas possam as diferentes formas de expressão ser, elas devem ser protegidas.

Nas palavras de Ronald Dworkin, a essência da visão negativa de liberdade inclui liberdade de ofender e isso se aplica não só a expressões heroicas, mas também àquelas de mau gosto (DWORKIN, 2006, p. 351). No entanto, o que essa visão não parece reconhecer é que a pornografia não significa somente uma odiosa forma de expressão, ela afeta a compreensão das mulheres sobre elas mesmas e a visão que é construída pela sociedade acerca das mulheres (RIBEIRO, 2017, p 133). Além disso, esse tipo de argumento legitima qualquer outra forma de expressão preconceituosa e prejudicial ao outro, já que elas são todas visões odiosas do outro.

Tal tipo de argumento encara a pornografia como um preço necessário a se pagar pela democracia, lidando com seus efeitos como uma forma de difamação ${ }^{28}$. Todavia, seus efeitos vão além de ofender, eles mostram um estereótipo de mulher que contribui com a desigualdade 
de gênero já existente. A pornografia não é somente uma opinião desfavorável, a pornografia reforça as diferenças e a subordinação, reforçando por consequência a desigualdade.

0 tradicional conceito negativo de liberdade deriva das ideias de John Stuart Mill de que a verdade tem uma melhor chance de aparecer quando há um livre mercado de ideias livremente debatidas e publicizadas. Ocorre que o mercado livre de ideias é uma finalidade buscada pela liberdade de expressão que exige a presença de um ambiente igualitário, onde todas as ideias possam surgir e ser devidamente escutadas (RIBEIRO, 2018, p. 52-53).

Assim, o que tais defensores não encaram é que para haver um livre mercado de ideias, onde as ideias possam ser transmitidas livremente e acessadas pela vontade do público, deve-se haver igualdade e pluralidade discursiva. Ocorre que, em nossas sociedades hierarquizadas, observa-se que nem todos tem o mesmo acesso a expressão de suas ideias: alguns indivíduos ou grupos têm mais acesso ao discurso do que outros, e a liberdade de expressão de alguns pode obstruir a liberdade de expressão de outros.

Desta forma, alguns indivíduos são sistematicamente silenciados pela expressão de outros (FISS, 2005, p. 58), como a mulher na pornografia. Na sociedade, aqueles que têm mais poder têm mais acesso ao discurso do que aqueles que são vulneráveis. Numa sociedade desigual em gênero, o discurso do poder impressiona (MACKINNON, 1989, p. 205).

Apesar de ser necessário proteger a possibilidade de ideias opostas, chocantes e até ofensivas para proteger a liberdade de expressão, deve se observar que em alguns momentos estas ideias podem ser restringidas pelo bem de outros direitos em conflito, especialmente quando eles atingem grupos vulneráveis e/ou minorias (RIBEIRO, 2017, p. 197 e ss.).

O debate expõe a tensão entre aqueles que entendem ser prioritária a proteção à autonomia do discurso, demandando do Estado uma abstenção, e aqueles que percebem a liberdade de expressão como um instrumento para a promoção da diversidade na esfera pública/social, demandando uma posição ativa do estado ao franquear ou expandir o acesso ao espaço público a grupos distintos. 
O Estado pode desempenhar um papel de inimigo mortal das liberdades ou um aliado vital delas (FISS, 2005, p. 28). Nesse balanço delicado, o excesso de interferência do Estado pode conduzir a um Estado totalitário e controlador, ou, de outro lado, sua ausência pode levar a exclusão dos debates públicos de grupos desfavorecidos em privilégio de grupos hegemônicos.

A concentração do poder privado também impacta a liberdade e, por vezes, a intervenção do Estado é necessária para opor essas forças (FISS, 2005, p. 28). No caso da pornografia, manter a visão misógina de mulher significa limitar sua liberdade de expressão, uma vez que a visão oferecida sobre ela fragiliza a credibilidade de seu discurso e sua imagem na sociedade. Afinal de contas, conforme salienta Catherine Mackinnon, quem vai querer escutar uma mulher com um pênis na boca? (MACKINNON, 1992, p. 483-484), uma vez que essa é a iconografia de mulher construída pela pornografia.

Por outro lado, alguns podem argumentar que a proposição segundo a qual a liberdade de expressão inclui o direito de viver em circunstâncias que encorajem a pessoa a falar e o dever de outros de compreender e respeitar aquelas vozes não é uma premissa aceitável (DWORKIN, 2006, p. 372). Contudo, não parece se tratar de compreensão, mas de evitar um discurso que ofereça uma errônea compreensão sobre um refinado mecanismo de silenciar o discurso alheio, qual seja, descreditando o potencial de seus discursos (FISS, 2005, p. 58). 0 objetivo é reconhecer questões que são propostas diariamente e ouvir igualmente a todos os tipos de argumentos que respondem a elas.

Acerca das liberdades comunicativas, tradicionalmente formaramse duas grandes concepções sobre a forma de tutela das liberdades de expressão e de imprensa: a teoria libertária e a teoria democrática (BINEBOJM, PEREIRA NETO, 2005, p. 05). A teoria libertária centra-se na figura do autor da mensagem, do sujeito que realizou a atividade expressiva de ideias, pregando que a garantia da liberdade de expressão visa proteger fundamentalmente a autonomia privada e o direito à expressão do pensamento sem interferências externas, pugnando pelo cunho exclusivamente defensivo da liberdade de expressão (BINEBOJM, PEREIRA NETO, 2005, p. 06). 
A teoria democrática, por sua vez, centra-se na figura do destinatário da mensagem e entende que a garantia da liberdade de expressão consiste em um instrumento do autogoverno, de forma a permitir que os cidadãos possam ser informados sobre os assuntos de interesse geral e, tendo acesso a todas as ideias, estejam aptos para livremente formar as suas convicções, pugnando por um cunho protetivo da liberdade de expressão (BINEBOJM, PEREIRA NETO, 2005, p. 06).

Aqueles que advogam uma visão absoluta de liberdade não estão aptos a explicar o porquê do interesse daqueles que produzem o discurso deverem ter prioridade sobre aqueles cujos interesses se opõem a esse discurso (FISS, 2005, p. 58). Eles não reconhecem que quem quer que exerça sua liberdade de expressão carrega não apenas direitos, mas também deveres e responsabilidades.

Analisando a posição da Corte Europeia de Direitos Humanos sobre pornografia e liberdade de expressão (FISS, 2005, p. 58), é possível perceber que sua perspectiva sobre pornografia a trata como um problema que envolve a moral. A questão da violência de gênero causada pela pornografia e da manutenção de uma ordem androcêntrica de mundo, pautada na dominação masculina, não é enfrentada pela Corte Europeia de Direitos Humanos, o que enfraquece e ignora as demandas atinentes à promoção dos direitos das mulheres.

No caso Handyside vs. United Kingdom ${ }^{29}$, a Corte Europeia de Direitos Humanos entendeu que a liberdade de expressão do discurso poderia ser restringida em detrimento da proteção da moral, nos termos do artigo 10(2). 0 caso referia-se a condenação do senhor Richard Handyside proprietário de uma editora em Londres, que publicou, dentre outros livros, o Pequeno Livro vermelho (The Little Red Schoobook), de teor obsceno. 0 referido livro já tinha sido publicado em diversos outros países.

O Sr. Handyside depois de traduzir o livro, com o apoio de um grupo de crianças e professores, pretendia publicá-lo em 1971. Depois de uma série de reclamações quanto ao livro, o Director Chief Prosecutor instaurou inquérito e conseguiu um mandado de prisão contra o editor, bem como apreender material gráfico ligado à publicação, sob vigência do Obscene Publication Act 1959/196430. Citado sob acusação de ter material obsceno, o Sr. Handyside tentou evitar a venda de livros, mas 
após toda publicidade já feita e a discussão que tinha levantado, isto não foi possível. No mesmo ano ele foi condenado à pena de multa.

0 primeiro ponto a ser destacado é que a restrição à liberdade de expressão alegadamente sofrida pelo Sr. Handyside foi baseada na Seção 2(1) do Obscene Publication Act de 1959 e emenda fornecida pela seção 1(1) Obsene Publication Act sob o argumento de que o livro corrompia e depravava seus leitores. Tal consideração evidencia a confusão já apontada entre o conceito de pornografia e obscenidade, que consequentemente conduz o foco da questão para a moral ${ }^{31}$.

Nesse sentido, a Corte Europeia de Direitos Humanos, juntamente com a Comissão ${ }^{32}$ e o Governo do Reino Unido, entenderam que apesar de vivermos em uma sociedade democrática, a liberdade de expressão constitui-se como um dos seus fundamentos essenciais, demandando pluralismo, tolerância e abertura de ideias. Desta forma, a destruição dos livros e as multas consistiram em medidas restritivas necessárias à liberdade de expressão, em proteção à moral, evitando a corrupção e a depravação do público do livro (pessoas jovens), nos termos do artigo 10 (2).

Quando questionada sobre a necessidade da restrição imposta pela Corte nacional, a Corte Europeia decidiu que "os Estados Contratantes têm cada um delineado sua aproximação à luz da situação de obtido em seus respectivos territórios; eles têm se deparado entre outras coisas com diferentes visões prevalecentes sobre a proteção da moral nas sociedades democráticas" (§57). 0 artigo 10(2) deixa ao Estado uma margem de apreciação que, no caso Handyside está ligado à moral, deixando uma discricionariedade ainda maior.

Este tipo de aproximação discricionária é problemática na medida em que, de um lado, deixa o indivíduo num estado de insegurança jurídica em relação a suas próprias ações, e, de outro lado, não encara propriamente o real problema da pornografia. Esta mesma tendência foi observada em Perrin v. United Kingdom, Müller and Others v. Switzerland, Wingrove v. the United Kingdom ${ }^{33}$.

É notável que a Corte não percebe as mudanças advindas com o tempo em relação à pornografia, tendo em conta que confere o mesmo tratamento ao tema desde 1970. Uma possível explicação para isso é que o 
problema da pornografia não é moral, como se demonstrou nos parágrafos anteriores. Nas precisas palavras de Paul Johnson, "a jurisprudência de Estrasburgo passou ao largo de ser perturbada pela 'Era da Internet' e com isso, no que tange a pornografia, confere aos Estados Contratantes uma larga discricionariedade para determinar o standard doméstico de moral e as medidas necessárias para protegê-la" (JOHNSON, 2014, p. 10).

Outrossim, a Corte Europeia de Direitos Humanos não enfrenta as diferenças entre pornografia infantil e adulta, ao tratar do mérito. É um fato que ambas partem da mesma problemática, no entanto, a pornografia infantil está relacionada a uma ainda mais profunda questão de formação humana, tornando mais sensível o tópico que deve ser separadamente analisado.

No que tange a relação entre o direito a ter sua vida privada respeitada, a pornografia será analisada sob o a luz do artigo 8 da Convenção ${ }^{34}$, de forma similar ao artigo 10 , podendo haver exceções reguladas pela lei, quando necessário a uma sociedade democrática.

No caso Pay v. United Kingdom o apelante reclamava ter sido suspenso e demitido de seu cargo de probation officer com a incumbência de tratar de pessoas que cometeram crimes sexuais, depois que seus patrões descobriram que ele era membro e diretor de uma organização que produzia e fornecia produtos ligados $\mathrm{BDSM}^{35}$, uma prática que está conectada a clubes privados nos quais, com consentimento, a mulher é dominada pelo homem, como regra.

A Corte Europeia de Direitos Humanos afirmou que "era importante que ele mantivesse o respeito dos ofensores que estavam sob sua supervisão e também a confiança do público em geral e vítimas de crimes sexuais em particular". Merece destaque a relação existente na argumentação da Corte entre o crime de cunho sexual e a afeição do apelante à pornografia. Ora, se a pornografia não incentiva comportamentos, não haveria razão para preocupações com a confiança das vítimas, afinal, seria possível que alguém que gostasse de pornografia tivesse uma conduta sexual inofensiva.

A reclamação não foi admitida sob a alegação de que o apelante não podia evitar publicidade do que supostamente seria sua vida privada. No entanto, o principal aspecto para essa pesquisa deveria ser: por que os empregadores e a Corte ligaram as práticas sexuais do apelante com seu 
papel em tratar ofensores sexuais? A resposta parece clara, em ambas a violência e o desrespeito à condição de seres humanos da mulher são evidentes $^{36}$.

Por último, mas não menos importante, tem-se a abordagem da pornografia sob a égide da proibição ao tratamento degradante nos termos do artigo $3^{37}$. Tradicionalmente, o artigo é invocado em uma expressiva diversidade de demandas, o que vem levando a Corte Europeia de Direitos Humanos a adotar padrões conservadores restringindo sua aplicação. Primeiro, o artigo 3 tem uma aplicação mais positiva, obrigando o Estado a proteger o indivíduo da tortura, da desumanidade, do tratamento ou punição degradantes.

Além disso, para verificar o que é tratamento degradante, a Corte Europeia de Direitos Humanos estabeleceu standards restritos como: a ação reclamada deve produzir efeitos sobre o apelante, produzindo na vítima 'sentimentos como medo, angústia e inferioridade capazes de humilha-la e rebaixa-la' (JOHNSON, 2014, p. 16).

No que diz respeito à pornografia adulta, até agora a Corte não se manifestou significativamente sobre isso. No entanto, de forma residual, no caso Toomey v. Reino Unido, o apelante reclamava estar sendo submetido à pornografia no tratamento realizado na "recarcerização". A Corte chegou à conclusão de que a submissão do apelante ao programa, apesar de humilhante não poderia ser degradante nos termos no artigo 3, levando em consideração seu contexto.

0 poder da pornografia de rebaixar e de humilhar é considerado um aspecto relevante para permitir a criação de uma regulação dessa forma de imagem sexual, tendo em conta seu potencial para gerar efeitos na construção da realidade social das pessoas (JOHNSON, 2014, p. 16). A partir deste ponto de vista será possível apontar a falha do Estado em regular certas formas de pornografia, o que daria margem ao tratamento contrário ao artigo 3.

Esse tipo de demanda será cada vez mais comum já que, apesar de a maior parte dos Estados não criminalizar a pornografia adulta, existe uma resolução do Conselho Europeu demandando providências no que se refere à pornografia extrema ${ }^{38}$, tendência que já se concretizou, por 
exemplo, no Reino Unido, através da parte 5, seções 63 a 67 do Ato da Justiça Criminal e Imigração de 2008.

As considerações mencionadas acima sobre a pornografia extrema tornam inconteste que este tipo de pornografia se adequa ao critério da degradação. Ademais, outra possibilidade é combinar o artigo 3 com o artigo $14^{39}$ para argumentar que o tratamento conferido pela pornografia à mulher consiste em um tratamento degradante e discriminatório no que tange à sexualidade. Nos dois casos, incluindo ou não o artigo 14, seria necessário enfrentar o limiar restrito da Corte Europeia de Direitos Humanos quanto a nível mínimo de severidade requerido no âmbito do artigo 3.

De uma forma ou de outra, pode-se afirmar que o sistema europeu de direitos humanos não oferece instrumentos de proteção às mulheres nas questões que envolvem a pornografia, na medida em que não leva em consideração os debates feministas existentes sobre o tema e não encara a pornografia sob o viés da desigualdade de gênero e dos seus impactos na construção da realidade social, em especial no que tange o incentive da violência contra a mulher.

Apesar de se preocupar com os direitos das mulheres e rechaçar tratamentos desumanos e degradantes e formas de manifestação da violência de gênero, o sistema europeu de direitos humanos não enfrentou a questão da pornografia sob o viés das mulheres - seja observando a necessidade da sua regulamentação ou da sua condenação, diante da violência gerada -, mas o fez pela perspectiva da liberdade de expressão dos pornógrafos e de seus consumidores.

\section{CONCLUSÃO}

Um exame crítico da jurisprudência da Corte Europeia de Direitos Humanos sobre pornografia leva a conclusão da necessidade de seu desenvolvimento e atualização, pois na maior parte dos casos a pornografia é tratada como um problema moral e não são enfrentados assuntos como sua influência na imagem da mulher e na formação de sua identidade de subordinação, na reprodução da misoginia e reforço da discriminação. 
Outrossim, tendo em vista que os Estados-Partes têm sua margem de apreciação baseada na moral, a Corte Europeia de Direitos Humanos propicia uma larga margem de discricionariedade e deixa os indivíduos na insegurança de não saber quais os limites da abordagem gráfica do sexo ou da sexualidade.

Pelos casos coletados é possível notar que, mesmo quando a corte protege a sociedade da pornografia, ela protege pela fundamentação da ofensa à moralidade sexual masculina dominante, que passa ao largo de enfrentar a real questão em comento, qual seja, a visão de mulher que a pornografia oferece e a violência de gênero perpetuada por ela. A fundamentação está longe de ser um detalhe trivial, tal opção faz diferença na afirmação e no reconhecimento de questões de relevância da mulher na sociedade e proteção adequada dos direitos humanos da mulher.

Por essas razões, urge uma visão contemporânea da questão que proporcione a melhor proteção aos direitos humanos da mulher no que se refere aos materiais pornográficos, a realidade social construída e corroborada por eles, bem como a violência de gênero envolvida na sua confecção e em razão do seu consumo.

Nesse contexto, para que haja a proteção dos direitos humanos das mulheres, o tratamento da pornografia a ser realizado pelo sistema europeu de direitos humanos - e pelos ordenamentos jurídicos em geral - deve levar em consideração as demandas provenientes das teorias feministas, seja através da necessidade de regulamentação do trabalho sexual, para a proteção das mulheres que se encontram na indústria pornográfica; seja através da abolição da pornografia ou, alternativamente, criação de medidas destinadas a proteger as mulheres que se encontram em situação de violência em razão da pornografia.

\section{NOTAS}

1 Na definição do dicionário Oxford de língua inglesa: "n.writings or pictures or films etc. that are intented to stimulate erotic feeling by description or portrayal of sexual activity." (grifo nosso) Oxford Senior Dictionary, Oxford University Press, 1981, p. 484.

2 Livre tradução da autora do texto de Diana Russel. Aliás, o que ela conceitua como pornografia heterossexual, MacKinnon e outras autores definem como pornografia convencional ou simplesmente pornografia. Isso significa que qualquer material cujo alvo seja homem heteressexual (mesmo mostrando relações gay) e público gay que mostre o conceito tradicional de mulheres operando uma posição de subalternidade pertence ao conceito. 
3 Tradução livre das autoras: "the graphic sexually explicit subordination of women through pictures and/or words

4 A indústria pornográfica explora mulheres pobres e vulneráveis. De acordo com dados médicos, essas mulheres são submetidas a um alto risco de contrair HIV, gonorreia retal, clamidia nos olhos. Adult Industry Medical Health Care Foundation. apud DINES, 2010, , p. xxviii.

5 De acordo com Pierre Bourdieu, "Tudo, na gênese do habitus feminino e nas endições sociais de sua realização, concorre para fazer a experiência universal do corpo-para-o-outro, incessantemente exposto à objetificação operada pelo olhar e pelo discurso dos outros". BOURDIEU, 2002, p. 101.

6 Ausência de intimidade, manutenção de ereção por lapso temporal prolongado, identificação do tamanho do pênis e comportamentos sexuais violentos com a virilidade masculina são alguns dos impactos negativos causados na vida dos homens.

7 No ambito da filosofia da linguagem, J. L Austin trouxe a noção de atos de fala como atos perfomativos, rompendo com a superação tradicional entre atos perfomartivos e atos constatativos. Segundo o autor, a linguagem é um fenomeno capaz de interferer e modificar a realidade, nao podendo ser vista apenas como um instituto meramente descritivo. Nesse sentido: AUSTIN, 1990, p. 21 e ss

8 De acordo com Andrea Dworkin, a pornografia é o DNA da dominação masculine, que funciona através do fortalecimento de dogmas estruturantes, como : a autoafirmação metafísica; a força física; a capacidade de aterrorizar; o poder de nomear; o poder de possuir; o poder do dinheiro; e o poder do sexo. DWORKIN, 1989, pp. 13-47.

9 Sobre a dominação masculina, vide: BOURDIEU, 2002.

10 Elementos contidos na definição de pornografia extraída de Catherine Mackinnon e Andrea Dworkin. Vide: DWORKIN, Andrea R.; MACKINNON, 1989, p. 36.

11 De acordo com Bernard Williams, existem dois elementos caracterizadores da essência humana: reação a dor e senso de auto-respeito. Vide: MACKINNON, 1989, p. 210.

12 A objetificação da mulher pela pornografia é minuciosamente analisada por Andrea Dworkin, em: DWORKIN,1989, p. 130 e ss.

13 David Le Breton observa que o corpo não pode ser analisado de forma dissociada da pessoa que ele representa, devendo ser afastado o risco da fragmentação corporal. Nesse sentido: BRETON, 2007, p. 26.

14 Para uma análise mais completa sobre as formas de violência geradas pela pornografia, vide: RIBEIRO, 2017

15 Classificação de violência retirada da Lei no $11.340 / 06$

16 Conceito extraído do artigo 7ํㅜ, I da Lei no $11.340 / 06$

17 Conceito extraído do artigo 7ํㅡㄴ, II da Lei no $11.340 / 06$

18 Conceito extraído do artigo 7으, III da Lei no $11.340 / 06$

19 Conceito extraído do artigo 70, IV da Lei no $11.340 / 06$

20 Conduta tipificada como calúnia, nos termos do artigo 138 do Código Penal Brasileiro.

21 Conduta tipificada como difamação, nos termos do artigo 139 do Código Penal Brasileiro.

22 Conduta tipificada como injuria, nos termos do artigo 140 do Código Penal Brasileiro.

23 Conceito extraído do artigo 7ํㅡ, $\mathrm{V}$ da Lei no $11.340 / 06$

24 Nesse sentido, vale a pena conferir a teoria da causalidade social construída por RUSSEL, 1994, p. 121-122.

25 The difficulty pointed regarding the absence of a clear harm during the Vitorian period, no longer is applicable, since, provided that pornography walks apart from moral. The harm would no longer be poison, pollution and infestation, but physical and psychological violence against woman. LEWIS, 2003, p 145-146.

26 No início do século XX, o parlamento inglês criou uma comissão para analisar a manutenção de tipos que envolviam a homossexualidade masculina e a prostituição feminina. 0 relatório final da comissão passou a ser conhecido como Wolfenden Report. A partir dele, surgiram duas linhas de debate. A primeira defendia que a reprovação moral de uma conduta seria suficiente para a sua reprovação jurídica (Lord Devlin), e a segunda entendia que a avaliação moral contrária da maioria dos membros da sociedade seria insuficiente para que a conduta fosse tipificada (Hart). Até hoje, a doutrina analisa esse debate a partir das posições contrárias de Devlin e Hart. 
27 Mais informaçõs sobre o debate histórico, vide e LEWIS, 2003

28 Vide US Supreme Court New York Times v. Sulivan

29 Disponível em: http://www.hudoc.echr.coe.int/webservices/content/pdf/001-57499?TID. Acesso em 18 de novembro de 2016.

30 Originária de 1857, quando proibia a publicação de literatura obscena, possibilitando algumas medidas relativas ao poder de polícia necessário a busca e apreensão do material, a lei foi modificada em 1959 e 1964, estabelecendo critérios para a avaliação e interesses que deveriam preponderar quando a obra tivesse por base a arte, literatura, ciência ou aprendizado. Finalmente, em 1977 a legislação foi novamente modificada para a inclusão de filmes, estando vigente até hoje. Disponível em: https://www.britannica.com/event/Obscene-Publications-Act.Acesso em: 18 de novembro de 2018.

31 O livro, em uma de suas passagens falando sobre pornografia (p 103-105, de acordo como relatória da Corte) contém os seguintes dizeres: “'Porn is a harmless pleasure if it isn't taken seriously and believed to be real life. Anybody who mistakes it for reality will be greatly disappointed. But it's quite possible that you may get some good ideas from it and you may find something which looks interesting and that you haven't tried before." Isso mostra como pornografia é uma forma de influenciar pessoas e construer suas visões.

320 presente caso foi julgado antes do advento do Procotolo n 11 à Convenção Europeia Convenção Europeia dos Direitos do Homem e das Liberdades Fundamentais, relativo à Reestruturação do Mecanismo de Controlo Estabelecido pela Convenção, assinado em 1994, que extinguiu a antiga estrutura do sistema europeu de direitos humanos, formado pela Comissão e Corte Europeias, unificando a sua estrutura na Corte Europeia de Direitos Humanos, que acumulou competências e assumiu papel de maior relevância.

33 No caso Perrin v. United Kingdom, foi usado o precedente do caso Handyside para justificar a não reversão da condenação do oficial Perrin, que foi apontado nos termos da Obscene Publications Act por ter entrado (em um dos computadores da Polícia inglesa) num site de pornografia, envolvendo pessoas cobertas com fezes, coprofilia, coprofagia, e homens envolvidos em fellatio. Disponível em: http://echr.ketse.com/doc/5446.03-en-20051018/view/. Acesso em: 15 de novembro de 2016. No caso Muller and Others v. Switzerland, em 1988, os apelantes montaram uma exposição, aberta e bastante divulgada, de arte contemporânea, na qual incluia-se três imagens explícitias de fellatio, sodomia e sexo com animais. No dia da inauguração o promotor começou procedimentos que requeriam sua destruição, sob alegação de que eram obscenos. Durante o procedimento criminal as imagens foram confiscadas e os apelantes multados, tendo recorrido à Corte. Disponível em: https://www.article19.org/resources.php/resource/2599/en/ muller-and-others-v.-switzerland. Acesso em: 15 de novembro de 2016. Em 1988, o Diretor Nigel Wingrove produziu um filme em que simulava as alucinações de Santa Teresa D’Avila chamado "Visões de êxtase" no qual a santa tinha visões de Jesus, que envolviam sensualidade. 0 filme não conseguiu a licença para reprodução quando submetido ao conselhor de classificação. 0 director recorreu, até que foi definitivamente negado. Em 1989, Wingrove apelou à Corte, que manteve adecisão do Judiciário inglês. Disponível em: http:// hudoc.echr.coe.int/app/conversion/ pdf/?library...id.... Acesso em: 16 de novembro de 2016.

34 ARTICLE 8 Right to respect for private and family life 1. Everyone has the right to respect for his private and family life, his home and his correspondence. 2 . There shall be no interference by a public authority with the exercise of this right except such as is in accordance with the law and is necessary in a democratic society in the interests of national security, public safety or the economic wellbeing of the country, for the prevention of disorder or crime, for the protection of health or morals, or for the protection of the rights and freedoms of others.

35 No idioma original "bondage, discipline, sadism, masochism".

36 Sobre o tema, existem duas posições teóricas diferentes a respeito dos impactos do consume da pornografia na vida dos seus consumidores: de um lado, a teoria da catarse determina que a pornografia é utilizada como válvula de escape pelos seus consumidores; de outro, a teoria da imitação sustenta que quanto mais acesso aos materiais pornográficos, mais se quer reproduzir aquilo que foi visto (OGIEN, 2005; PRADA, p. 18, RUSSELL, 1994). As feministas pró-pornografia questionam a relação de causalidade entre a pornografia e a violência de gênero, pois sustentam 
que não existe uma comprovação efetiva e consistente dessa relação, uma vez que as pesquisas empíricas já realizadas sobre o tema chegam a resultados diversos e apresentam problemas normativos e metodológicos com relação a interpretação dos seus dados (PRADA, 2010, p. 18). Ocorre que existem pesquisas científicas sérias que já comprovaram os impactos negativos do consumo da pornografia,(RUSSELL, 1994), o que demonstra a danosidade desses materiais em determinados casos, sendo essa tese defendida pelo movimento feminista anti-pornografia e também a posição adotada no presente artigo.

37 ARTICLE 3 Prohibition of torture No one shall be subjected to torture or to inhuman or degrading treatment or punishment.

38 A pornografia extrema está ligada a casos em que esta é levada ao extremo de atentar contra a vida de pessoas. Neste sentido, as seções 63 a 67 do act criminalize a conduta de possuir imagens pornográficas que representem atos que ameacem a vida de uma pessoa; atos que resultem ou possam resultar em sérios ferimentos ao ânus da pesssoa, bem como seios e genitália; bestialidade ou necrofilia.

39 ARTICLE 14 Prohibition of discrimination The enjoyment of the rights and freedoms set forth in this Convention shall be secured without discrimination on any ground such as sex, race, colour, language, religion, political or other opinion, national or social origin, association with a national minority, property, birth or other status.

\section{REFERÊNCIAS}

AUSTIN, J. L. Quando dizer é fazer: palavras e ação. Porto Alegre: Editora Artes Médicas, 1990.

BITENCOURT, Cézar Roberto. Tratado de direito penal: parte geral. 17. ed. São Paulo: Saraiva, 2012.

BOURDIEU, Pierre. A dominação masculina. Tradução de Maria Helena Kuhner. Rio de Janeiro: Bertrand Brasil, 2002.

BOZON, Michel. Sociologia da sexualidade. Tradução de Maria de Lourdes Menezes. Rio de Janeiro: Editora FGV, 2004.

BRASIL. Lei n. 11.340, 07 de Agosto de 2006. Disponível em: http://www. planalto.gov.br/ccivil_03/_ato2004-2006/2006/lei/l11340.htm. Acesso em: 01 maio 2017.

Código Penal. Disponível em: http://www.planalto.gov.br/ccivil_03/ decreto-lei/Del2848compilado.htm Acesso em: 01 maio 2017.

BRETON, David Le. A sociologia do corpo. 2. ed. Tradução de Sonia M. S. Fuhrmann. Petrópolis, RJ: Vozes, 2007. 
BUTLER, Judith. Lenguaje, poder e identidad. Tradução e prólogo de Javier Sáez y Beatriz Preciado. Madrid: Editorial síntesis, 1997.

CULTURE REFRAMED. Available in: < http://www.culturereframed.org/thecrisis>. Acesso em: 1.o jun. 2017.

DINES, Gail. Pornland: how porn has hijacked our sexuality. Boston: Beacon Press, 2010.

DWORKIN, Andrea. Pornography Men Possessing Women. Penguin Group, 1989.

DWORKIN, Andrea R.; MACKINNON, Catharine A. Pornography and Civil Rights: a new day for women's equality. Minneapolis: Organizing Against Pornography, 1989.

DWORKIN, Ronald. 0 direito da liberdade: a leitura moral da constituição norte-americana. São Paulo: Martins Fontes, 2006.

ECHOLS, Alice. The taming of the Id: feminist sexual politics, 1968-1983. Vance, Pleasure and Danger. Boston: G. K. Hall, 1983, p. 50-72.

FISS, Owen M. A ironia da liberdade de expressão: Estado, regulação e diversidade na esfera pública. Tradução e Prefácio de Gustavo Binenbojm e Caio Mário da Silva Pereira Neto. Rio de Janeiro: Renovar, 2005.

FERREIRA, Aurélio Buarque de Holanda. Novo dicionário da língua portuguesa, 2. ed. Editora Nova Fronteira, 1986.

FRAGOSO, Heleno Cláudio. Lições de direito penal: parte geral. 16. ed. Rio de Janeiro: Forense, 2003.

JOHNSON, Paul. Pornography and the European Convention on Human Rights. Porn Studies, 1:3, 315-336, 2014. DOI: 10.1080/23268743.2014.927706

LEWIS, Tom.Vitorian and Modern Legal Responses to Pornography. STEVENSON, Kim; ROWBOTHAM, Judith. Behaving badly: Social Panic and Moral Outrage Vitorian and Modern Parallels. Aldershot: Ashgate, 2003. 
MACKINNON, Catharine. Toward a feminist theory of the state. Cambridge, Massachusetts; London, England: Harvard University Press, 1989.

____. "Pornography, Civil Rights, and Speech" In: ITZIN, Catherine (Org.) Pornography: Women, Violence and Civil Libertities. Ozford University Press, 1992.

Only Words. Cambridge, Massachusetts: Harvard University Press, 1996.

NUCCI, Guilherme de Souza. Manual de direito penal. 12. ed. Rio de Janeiro: Gen Metodo, 2016.

OGIEN, Ruwen. Pensar la pornografia. Barcelona: Paidós, 2005.

OXFORD SENIOR DICTIONARY. Senior Dictionary. Oxford University Press, 1981.

PRADA, Nancy Prada. ¿Qué décimos las feministas sobre la pornografia? los orígenes de um debate. La manzada de la discórdia. Jan/Jun, v. 5, 1, p. 7-26, 2010.

PRECIADO, Paul Beatriz. Texto Junkie: sexo, drogas e biopolítica na era farmacopornográfica. N1-Edições, 2018.

RIBEIRO, Raisa Duarte da Silva. Discurso de ódio, violência de gênero e pornografia: entre a liberdade de expressão e a igualdade. Editora Multifoco, 2017.

Liberdade de expressão e discurso de ódio. Editora Multifoco, 2018.

RIBEIRO, Raisa Duarte da Silva; BARBOSA, Renata da Silva Athayde; COSTA, Rodrigo de Souza. Pornografia e violência de gênero: instrumentos de proteção da mulher em situação de violência. Revista IBCCRIM, n. 151, p. 417-456, 2019.

ROXIN, Claus. Que comportamentos pode o Estado proibir sob ameaça de pena? sobre a legitimação das proibições penais. In: Estudos de direito penal. 2. ed. Tradução de Luis Greco. Rio de Janeiro: Renovar. 2008. 
RUBIN, Gayle. Thinking sex: notes for a radical theory of the politics of sexuality. Vance, Pleasure and Danger. Boston: G. K. Hall, 1983, p. 267-319.

RUSSEL, Diana. Against pornography: the evidence of harm. Berkeley, California: Russell Publications, 1994.

SILVA, Tadeu Dix. Direito penal e liberdade de expressão no estado democrático de direito. São Paulo: IBCCRIM, 2000. v. 15.

TAVARES, JUAREZ. 0 consentimento do ofendido no direito penal. Revista UFPR. Disponível em: http://revistas.ufpr.br/direito/article/viewFile/7163/5114. Acesso em: 23 out. 2018.

UNITED NATIONS OFFICE ON DRUGS AND CRIME (UNODOC). Global Report in Trafficking. Persons. 2014. Disponível em: https://www.unodc.org/documents/ lpo-brazil//Topics_TIP/Publicacoes/GLOTIP_2014_full_report.pdf. Acesso em: 30 set. 2018.

UNITED NATIONS OFFICE ON DRUGS AND CRIME (UNODOC). Global Report in Trafficking. Persons, 2016. Disponível em: https://www.unodc.org/documents/ lpo-brazil//Topics_TIP/Publicacoes/2016_Global_Report_on_Trafficking_in_ Persons.pdf. Acesso em: 30 set. 2018.

VANCE, Carole S. Placer y peligro: explorando la sexualidade feminina. Madrid: Talasa, 1989.

Recedido em: 05-07-2017

Aprovado em: 04-07-2019

\section{Raisa Duarte da Silva Ribeiro}

Doutoranda pelo PPGD da Universidade Federal do Rio de Janeiro (UFRJ) na linha de Sociedade, Direitos Humanos e Arte. Mestre em Direito Constitucional pela Universidade Federal Fluminense. Especialista em Advocacia Pública e em Direito Público pela Universidade Candido Mendes e em Direitos Humanos pela Universidade de Coimbra (2012). Pesquisadora do Núcleo Interamericano de Direitos Humanos (NIDH-UFRJ).

E-mail: raisaribeiro@hotmail.com 


\section{Renata da Silva Athayde Barbosa}

Doutoranda em Direito Penal pela Universidade do Estado do Rio de Janeiro (UERJ). Bolsista de doutorado sanduíche pela CAPES na Universidade de Maastricht, Holanda (Processo no 88881.189244/2018-01). Mestre em Direito Constitucional pela Universidade Federal Fluminense (UFF). Especialista em Direito Público pela Universidade Cândido Mendes (UCAM). Especialista em Direito Penal Internacional pelo Instituto Internacional de Justiça Criminal e Direitos Humanos de Siracusa (Itália). Professora convidada na Especialização em Ciências Criminais e Segurança Pública da Universidade do Estado do Rio de Janeiro (UERJ). Pesquisadora do Núcleo Interamericano de Direitos Humanos da Faculdade Nacional de Direito (NIDH-FND).

E-mail: renataabarbosa@gmail.com

\section{Rodrigo de Souza Costa}

Doutor e mestre em Direito pela Universidade do Estado do Rio de Janeiro (UERJ). Atualmente é secretário geral adjunto do Grupo Brasileiro da Associação Internacional de Direito Penal. Professor convidado do Master em Éxecution Penal et Droits de l'Homme feito em parceria entre a Université de Pau et des Pays de l?Adour, a Université de Bordeaux IV e a ENAP - École Nationale d'Administration Pénitentiaire. Professor adjunto de Direito Penal da Universidade Federal Fluminense (UFF).

E-mail: rodrigo.s.costa02@hotmail.com

Universidade do Estado do Rio de Janeiro - UERJ. Programa de Pós-Graduação São Francisco Xavier, 524 - sala 1006, 1ํo andar, bloco A. Maracanã, Rio de Janeiro - RJ. CEP 20550-900 